\title{
Study on Association between BMI and Vitamin D Levels in South Indian Rural Population
}

\author{
Ponnambalam A. ${ }^{1}$, Arun M. ${ }^{2 *}$, Prabhu G. ${ }^{3}$ \\ DOI: https://doi.org/10.17511/ijmrr.2021.i04.02 \\ 1 A Ponnambalam, Associate Professor, Department of Medicine, Sri Venkateshwara Medical College Hospital and Research Centre, , \\ Pondicherry, India. \\ 2* Arun M, Assistant professor, Department of General Medicine, Sri Venkateshwara Medical College Hospital and Research Centre, , \\ Pondicherry, India. \\ 3 Prabhu G, Professor, Department of General Medicine, Sri Venkateshwara Medical College Hospital and Research Centre, , Pondicherry, \\ India.
}

Introduction: Vitamin D deficiency is a global health problem worldwide and is considered to be a pandemic with implications for compromised bone health and other chronic diseases. A few studies have examined the association between vitamin D status and body mass index (BMI). However, prospective data using the biomarker serum 25-hydroxyvitamin D 25(OH) D3 are limited and therefore examined in the present study. Methods: Participants were selected from subjects attending to Medicine Outpatient Department (OPD) in Sri Venkateshwara Medical College Hospital \& Research Centre (SVMCH \& RC) willing to participate in the present study between Jan 2020 to Dec 2020. Anthropometric measurements, personal, medical history questionnaire, food frequency questionnaire (FFQ) for vitamin $D$, and sun exposure questionnaire were collected from all the participants in the present study, blood samples for serum 25(OH)D3 were collected from all subjects. Results: Our study showed that the majority of healthy individual cases of the study i.e., $68.0 \%$ have a deficiency in vitamin D status, while $68.0 \%$ have $\leq 20 \mathrm{ng} / \mathrm{dl}$ in vitamin $\mathrm{D}$, and $32.0 \%$ in $>20 \mathrm{ng} / \mathrm{dl}$. Moreover, the study showed a negative association between the level of circulating 25(OH) D3 and BMI. Conclusion: This study demonstrated that the association between BMI and $25(\mathrm{OH}) \mathrm{D}$ concentrations in populations from south India can be seen across different age groups and in both men and women. The study also exemplified that higher BMI leads to lower vitamin D status, providing evidence for the role of obesity as a causal risk factor for the development of vitamin $D$ deficiency.

Keywords: Body mass index, Vitamin D, Obesity

Corresponding Author

Arun M, Assistant professor, Department of General Medicine, Sri Venkateshwara Medical College Hospital and Research Centre, , Pondicherry, India. Email: arjun.manivannan2018@gmail.com
How to Cite this Article

A Ponnambalam, Arun M, Prabhu G. Study on Association between BMI and Vitamin D Levels in South Indian Rural Population. Int J Med Res Rev. 2021;9(4):213-218.

Available From

https://ijmrr.medresearch.in/index.php/ijmrr/article/ view/1305
To Browse

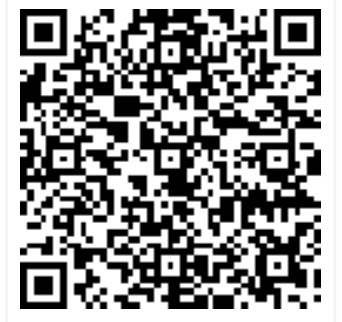

Manuscript Received 2021-05-28

Conflict of Interest No
Review Round 1 2021-06-08

Funding

Nil
Review Round 2 2021-06-18

Ethical Approval Yes
Review Round 3 2021-06-29

Plagiarism X-checker $8 \%$
Accepted 2021-07-22

Note

(C) 2021 by A Ponnambalam, Arun M, Prabhu G and Published by Siddharth Health Research and Social Welfare Society. This is an Open Access article licensed under a Creative Commons Attribution 4.0 International License https://creativecommons.org/licenses/by/4.0/ unported [CC BY 4.0]. 


\section{Introduction}

The prevalence of obesity has increased in the last two decades and it is presently the most common and costly nutritional problem. [1-4]. In India, onethird of the population is affected by obesity, according to the National Health and Nutrition Examination Survey. [5]. Despite a known genetic contribution, the increase in obesity prevalence has been largely attributed to lifestyle changes, which means that it is amenable to modification through public health and other interventions. [6]. Vitamin D deficiency is another increasingly prevalent public health concern in developed countries, [7-9]. and there is evidence that vitamin D metabolism, storage, and action both influence and are influenced by adiposity.

Observational studies have reported an increased risk of vitamin $D$ deficiency in those who are obese; however, the underlying explanations and direction of causality are unclear. [10]. Active vitamin D (1,25-dihydroxy vitamin D) may influence the mobilization of free fatty acids from the adipose tissue. [11]. In vitro experiments in rats have also shown that large doses of vitamin D2 lead to increases in energy expenditure due to the uncoupling of oxidative phosphorylation in adipose tissues. [12]. However, randomized controlled trials (RCTs) testing the effect of vitamin $D$ supplementation on weight loss in obese or overweight individuals have provided inconsistent findings. [13-15].

It has also been suggested that obesity could result from an excessive adaptive winter response and that the decline in vitamin D skin synthesis due to reduced sunlight exposure, contributes to the tendency to increase fat mass during the colder periods of the year. $[16,17]$. However, vitamin $D$ is stored in the adipose tissue and, hence, perhaps the most likely explanation for the association is that the larger storage capacity for vitamin $D$ in obese individuals leads to lower circulating 25hydroxyvitamin $\mathrm{D}[25(\mathrm{OH}) \mathrm{D}]$ concentrations, a marker for nutritional status. [18]. If lower vitamin D intake/status is causally related to obesity, a genetic variant associated with lower $25(\mathrm{OH})$ D concentrations should be associated with higher body mass index (BMI) (in proportion to the effect on $25(\mathrm{OH}) \mathrm{D})$. Conversely, if obesity leads to lower vitamin $D$ status, then genetic variants associated with higher BMI should be related to lower 25 $(\mathrm{OH}) \mathrm{D}$ concentrations.
The genetic associations, unlike the directly observed associations for vitamin D intake/status, should be less prone to confounding by lifestyle and socio-economic factors and be free from reverse causation as genotypes are invariant and assigned at random, before conception. The use of multiple SNPs to index the intermediate exposure of interest increases power and reduces the risk of alternative biological pathways (pleiotropy) affecting the observed associations between the genotype and the outcome. $[19,20]$. With the above evidence, this study aims to evaluate the level of vitamin $D$ status among healthy individuals and examine the relation between BMI and 25(OH)D in a cross-sectional sample of 100 men and women ranging in age from 18-75 years.

\section{Methodology}

Study Design: A Cross-sectional study was conducted between Jan 2020 to Dec 2020, in SVMCH \& RC to access Vitamin D levels among different subjects with various ranges of BMI. In this study, 100 patients were enrolled. Participants were selected from subjects attending to Medicine OPD in SVMCH \& RC willing to participate in the present study. Inclusion criteria: All healthy subjects who were willing to participate in the study, both male and female were included. Subjects with comorbidities were also included. Exclusion criteria: Subjects with known thyroid disorders, malignancy, and who were on Vitamin $D$ supplementation were excluded from the study. Anthropometric measurements, personal, medical history questionnaire, food frequency questionnaire (FFQ) for vitamin $D$, and sun exposure questionnaire were collected from all the participants in the present study. Samples for serum 25(OH)D3 were also collected from all subjects. Approval of the Institutional ethics committee was obtained.

Statistical Analyses: Stratified sample and descriptive tools (Frequency distribution and graphs) used. Furthermore, examine the normality of data by Shapiro- Wilk tests and examine the relationship of $25(\mathrm{OH}) \mathrm{D}$ with other variables done by Pearson correlation analysis. Chi-square was used to test variables on vitamin D. All statistical analyses were performed by using SPSS (version 20) ( $p<0.05$ is considered statistically significant).

\section{Results}

Table 1 Age/sex distribution of the study population 


\begin{tabular}{|l|l|l|l|}
\hline \multirow{2}{*}{ Age } & \multicolumn{2}{|c|}{ Sex } & \multirow{2}{*}{ Total } \\
\cline { 2 - 3 } & Male & Female & \\
\hline $18-30$ & 03 & 03 & 06 \\
\hline $31-40$ & 10 & 06 & 16 \\
\hline $41-50$ & 11 & 27 & 38 \\
\hline $51-60$ & 10 & 10 & 20 \\
\hline$>60$ & 11 & 09 & 20 \\
\hline Total & 45 & 55 & 100 \\
\hline
\end{tabular}

In our study, we had the youngest patient with $18 y e a r s$ and the oldest patient with 78years. In the present study, we had maximum patients in the age group between 41 to 50 years as similar to various other studies. In our study male was $45 \%$ with females were $55 \%$.

Table-2: BMI distribution of the study population

\begin{tabular}{|l|l|l|l|}
\hline \multirow{2}{*}{ BMI } & \multicolumn{2}{c|}{ Sex } & \multirow{2}{*}{ Total } \\
\cline { 2 - 3 } & Male & Female & \\
\hline $18.5-20$ & - & - & - \\
\hline $20.1-25$ & 10 & 15 & 25 \\
\hline $25.1-30.0$ & 25 & 36 & 61 \\
\hline$>30.0$ & 10 & 04 & 14 \\
\hline Total & 45 & 55 & 100 \\
\hline
\end{tabular}

Table-3: Distribution of vitamin D levels among the study population

\begin{tabular}{|l|l|l|}
\hline \multicolumn{1}{|c|}{ Vitamin D $(\mathrm{ng} / \mathrm{ml})$} & No of patients & \multicolumn{1}{c|}{ Percentage (\%) } \\
\hline$\leq 20$ & 68 & 68 \\
\hline$>20$ & 32 & 32 \\
\hline Total & 100 & 100 \\
\hline
\end{tabular}

Table-4: Vitamin D levels among the study population

\begin{tabular}{|l|l|l|}
\hline \multicolumn{1}{|c|}{ Vitamin D $(\mathrm{ng} / \mathrm{ml})$} & \multicolumn{1}{|c|}{ Male $(\mathrm{n}=\mathbf{4 5})$} & \multicolumn{1}{c|}{ Female $(\mathrm{n}=\mathbf{5 5})$} \\
\hline$\leq 20$ & $18.4 \pm 6.4$ & $18.7 \pm 6.9$ \\
\hline$>20$ & $23.8 \pm 8.77$ & $22.7 \pm 8.2$ \\
\hline
\end{tabular}

Table-5: Vitamin D Vs BMI (with P-value)

\begin{tabular}{|l|l|l|l|l|}
\hline \multicolumn{1}{|c|}{ BMI } & \multicolumn{1}{c|}{ Mean } & \multicolumn{2}{c|}{ Vitamin D (ng/ml) } & \multirow{2}{*}{ p-Value } \\
\cline { 3 - 4 } & & $\leq 20$ & $>20$ & \\
\hline $18.5-20$ & & - & - & - \\
\hline $20.1-25$ & $22.87 \pm 7.28$ & $19.12 \pm 5.4$ & $21.97 \pm 6.4$ & $<0.01276$ \\
\hline $25.1-30.0$ & $27.14 \pm 8.97$ & $18.59 \pm 5.1$ & $22.14 \pm 7.14$ & $<0.02587$ \\
\hline$>30.0$ & $30.98 \pm 10.04$ & $18.28 \pm 4.9$ & $22.47 \pm 8.2$ & $<0.03945$ \\
\hline
\end{tabular}

\section{Discussion}

Vitamin D is a fat-soluble vitamin that functions as a pre-hormone and it is naturally present via a few foods or supplements. It can target many specific tissues in the body. Also, it promotes the absorption of calcium from the small intestine and the major biological and phosphate.
Vitamin $\mathrm{D}$ can be synthesized endogenously by direct sun exposure strike the skin and sun exposure, food and supplements is biologically interactions and must undergo two hydroxylations in the body. The first activation occurs in the liver which converts vitamin $D$ to 25-hydroxyvitamin D $(25(\mathrm{OH}) \mathrm{D})$, also known as calcidiol is the best measure for vitamin D level. [3]. The second occurs primarily in the kidney and forms the physiologically active 1 , 25-dihydroxyvitamin D (1,25(OH) D), also known as calcitriol.

Numerous characteristics such as body fat darker skin tone and physical activity also contribute to vitamin $D$ status. The prevalence of vitamin $D$ deficiency has become a major public health problem. Obesity, and vitamin D deficiency, is among the most important modifiable risk factors for several chronic diseases. Obesity and vitamin D status are known to be associated but the direction of the association and whether it is causal has been uncertain. We have presented genetic evidence that higher BMI leads to lower vitamin D status.

Conversely, our analyses provided no evidence for a causal role of vitamin $D$ in the development of obesity, although our study was not powered to detect very small effects. These results suggest that although increases in vitamin D status are not likely to help with weight regulation, increased risk of vitamin $D$ deficiency could contribute to the adverse health effects associated with obesity. The association between obesity and vitamin D status was remarkably consistent across the different populations included in our meta-analyses, being apparent both in men and in women, and the young and older cohorts alike.

Recent intervention studies have shown that obese individuals need higher vitamin $\mathrm{D}$ dosages than lean individuals to achieve the same 25(OH)D concentrations. [21,22]. Given that North America has one of the highest rates of obesity in the world. [23] our study highlights the importance of considering obesity as a risk factor for vitamin D deficiency with implications on the dosage requirements and possible targeting of relevant health promotion strategies. In our study we enrolled 100 patients. Male were 45 (45\%), Female were $55(55 \%)$. Most of the patients affected in the age group were $41-50$ years (38\%).

BMI level was calculated and tabulated. Most of the patients with BMI were 25.1-30 (61 patients). 
Dilution related to the greater volume of distribution has been recently proposed as the most likely explanation for the lower $25(\mathrm{OH}) \mathrm{D}$ concentrations in obese individuals. [24]. In that study, no evidence was found for reduced bioavailability through increased sequestration of vitamin $D$ in the adipose tissue, which had previously been suggested to contribute to the low 25(OH)D concentrations in obesity. [25].

It is also possible that differences in lifestyle could contribute to lower $25(\mathrm{OH}) \mathrm{D}$ concentrations in obese compared to normal-weight individuals, although the association between obesity and low $25(\mathrm{OH}) \mathrm{D}$ concentrations has been found to only modestly attenuate after adjustment for vitamin Drelated lifestyle and dietary factors. [9]. In the present study, serum Vitamin D levels were measured in 100 patients. It was found that $68 \%$ of the patients are less than 20ng/dl Vitamin D deficient and $32 \%$ had normal levels of more than $20 \mathrm{ng} / \mathrm{dl}$. In our study we found statistical significant between BMI and Vitamin D levels in obese patients.

No more study found for similar results. In contrast, associations between BMI and 25(OH)D within levels in the obesity range were consistently linear in studies included in our analyses (unpublished data), hence the observed association between higher BMI and lower $25(\mathrm{OH}) \mathrm{D}$ is likely to be informative in the context of obesity.

\section{Conclusion}

In conclusion, the present study demonstrated that the association between BMI and 25(OH)D concentrations in populations from south India can be seen across different age groups and in both men and women. The study also exemplified that higher BMI leads to lower vitamin D status, providing evidence for the role of obesity as a causal risk factor for the development of vitamin $D$ deficiency. The study findings suggest that population-level interventions to reduce obesity would be expected to lead to a reduction in the prevalence of vitamin $D$ deficiency.

\section{What does the study add to existing knowledge?}

The study shows evidence for the role of obesity as a causal risk factor for the development of vitamin $\mathrm{D}$ deficiency.

\section{Author contributions}

AP, MA collected the data, conducted this study, did data analysis. GP did manuscript drafting. All authors were involved in revising and approved the final version of the manuscript.

\section{Reference}

01. Baskin $M L$, Ard J, Franklin F, Allison DB. Prevalence of obesity in the United States. Obes Rev. 2005 Feb;6(1)5-7. doi: 10.1111/j.1467789X.2005.00165.x [Crossref][PubMed][Google Scholar]

02. Ogden $\mathrm{CL}$, Carroll MD, Curtin LR, Lamb MM, Flegal KM. Prevalence of high body mass index in US children and adolescents, 2007-2008. JAMA. 2010 Jan 20;303(3)242-9. doi: 10.1001/jama.2009.2012 [Crossref][PubMed] [Google Scholar]

03. Berghöfer A, Pischon T, Reinhold T, Apovian CM, Sharma AM, Willich SN. Obesity prevalence from a European perspective: a systematic review. BMC Public Health. 2008 Jun 5;8;200. doi: 10.1186/1471-2458-8-200 [Crossref][PubMed] [Google Scholar]

04. Zheng $W$, McLerran DF, Rolland B, Zhang $X$, Inoue $M$, Matsuo $K$, et al. Association between bodymass index and risk of death in more than 1 million Asians. N Engl J Med. 2011 Feb 24;364(8)719-29. doi: 10.1056/NEJMoa1010679 [Crossref][PubMed] [Google Scholar]

05. Flegal KM, Carroll MD, Kit BK, Ogden CL. Prevalence of obesity and trends in the distribution of body mass index among US adults, 1999-2010. JAMA. 2012 Feb 1;307(5)491-7. doi: 10.1001/jama.2012.39 [Crossref][PubMed][Google Scholar]

06. Vimaleswaran KS, Loos RJ. Progress in the genetics of common obesity and type 2 diabetes. Expert Rev Mol Med. 2010 Feb 26;12;e7. doi: $10.1017 / S 1462399410001389$ [Crossref][PubMed] [Google Scholar]

07. Ginde AA, Liu MC, Camargo CA Jr. Demographic differences and trends of vitamin $D$ insufficiency in the US population, 1988-2004. Arch Intern Med. 2009 Mar 23;169(6)626-32. doi: 10.1001/archinternmed.2008.604 [Crossref] [PubMed][Google Scholar] 
08. Lanham-New SA, Buttriss JL, Miles LM, Ashwell $M$, Berry JL, Boucher BJ, et al. Proceedings of the Rank Forum on Vitamin D. Br J Nutr. 2011 Jan;105(1)144-56. doi: 10.1017/S0007114510002576 [Crossref][PubMed] [Google Scholar]

09. Hyppönen E, Power C. Hypovitaminosis D in British adults at age $45 \mathrm{y}$ - nationwide cohort study of dietary and lifestyle predictors. Am J Clin Nutr. 2007 Mar;85(3)860-8. doi: 10.1093/ajcn/85.3.860 [Crossref][PubMed][Google Scholar]

10. Earthman CP, Beckman LM, Masodkar K, Sibley SD. The link between obesity and low circulating 25hydroxyvitamin D concentrations: considerations and implications. Int J Obes (Lond). 2012 Mar;36(3)387-96. doi: 10.1038/ijo.2011.119 [Crossref][PubMed][Google Scholar]

11. Shi H, Norman AW, Okamura WH, Sen A, Zemel MB. 1alpha,25-Dihydroxyvitamin D3 modulates human adipocyte metabolism via nongenomic action. FASEB J. 2001 Dec;15(14)2751-3. doi: 10.1096/fj.01-0584fje [Crossref][PubMed][Google Scholar]

12. Fassina G, Maragno I, Dorigo P, Contessa AR. Effect of vitamin D2 on hormone-stimulated lipolysis in vitro. Eur J Pharmacol. 1969 Feb;5(3)286-90. doi: 10.1016/0014-2999(69)90150-2 [Crossref] [PubMed][Google Scholar]

13. Sneve, M. , Y. Figenschau, and R. Jorde. "Supplementation with cholecalciferol does not result in weight reduction in overweight and obese subjects". European journal of endocrinology. 159;6(2008)675-684 [Crossref][PubMed][Google Scholar]

14. Zittermann A, Frisch S, Berthold HK, Götting C, Kuhn J, Kleesiek $\mathrm{K}$, et al. Vitamin D supplementation enhances the beneficial effects of weight loss on cardiovascular disease risk markers. Am J Clin Nutr. 2009 May;89(5)1321-7. doi: 10.3945/ajcn.2008.27004 [Crossref][PubMed] [Google Scholar]

15. Salehpour A, Shidfar F, Hosseinpanah F, Vafa $M$, Razaghi M, Hoshiarrad A, Gohari M. Vitamin D3 and the risk of CVD in overweight and obese women- a randomised controlled trial. $\mathrm{Br}$ J Nutr. 2012 Nov 28;108(10)1866-73. doi: 10.1017/S0007114512000098 [Crossref][PubMed] [Google Scholar]
16. Soares MJ, Murhadi LL, Kurpad AV, Chan She Ping-Delfos WL, Piers LS. Mechanistic roles for calcium and vitamin $D$ in the regulation of body weight. Obes Rev. 2012 Jul;13(7)592-605. doi: 10.1111/j.1467-789X.2012.00986.x [PubMed][Google Scholar]

[Crossref]

17. Foss YJ. Vitamin D deficiency is the cause of common obesity. Med Hypotheses. 2009 Mar;72(3)314-21. doi: 10.1016/j.mehy.2008.10.005 [Crossref][PubMed] [Google Scholar]

18. Wortsman J, Matsuoka LY, Chen TC, Lu Z, Holick MF. Decreased bioavailability of vitamin $D$ in obesity. Am J Clin Nutr. 2000 Sep;72(3)690-3. doi: 10.1093/ajcn/72.3.690 [Crossref][PubMed][Google Scholar]

19. Davey Smith G. Random allocation in observational data- how small but robust effects could facilitate hypothesis-free causal inference. Epidemiology. 2011 Jul;22(4)460-3; discussion 4678. doi: 10.1097/EDE.0b013e31821d0426 [Crossref] [PubMed][Google Scholar]

20. Palmer TM, Lawlor DA, Harbord RM, Sheehan $\mathrm{NA}$, Tobias $\mathrm{JH}$, Timpson $\mathrm{NJ}$, et al. Using multiple genetic variants as instrumental variables for modifiable risk factors. Stat Methods Med Res. 2012 Jun;21(3)223-42. doi: 10.1177/0962280210394459 [Crossref][PubMed][Google Scholar]

21. Jorde $R$, Sneve M, Emaus N, Figenschau $Y$, Grimnes $G$. Cross-sectional and longitudinal relation between serum 25-hydroxyvitamin D and body mass index- the Troms $\varnothing$ study. Eur J Nutr. 2010 Oct;49(7)401-7. doi: 10.1007/s00394-010-0098-7 [Crossref][PubMed][Google Scholar]

22. Lee $P$, Greenfield JR, Seibel MJ, Eisman JA, Center JR. Adequacy of vitamin $D$ replacement in severe deficiency is dependent on body mass index. Am J Med. 2009 Nov;122(11)1056-60. doi: 10.1016/j.amjmed.2009.06.008 [Crossref][PubMed] [Google Scholar]

23. Bassett DR Jr, Pucher J, Buehler R, Thompson $\mathrm{DL}$, Crouter SE. Walking, cycling, and obesity rates in Europe, North America, and Australia. J Phys Act Health. 2008 Nov;5(6)795-814. doi: 10.1123/jpah.5.6.795 [Crossref][PubMed][Google Scholar] 
24. Drincic AT, Armas LA, Van Diest EE, Heaney RP. Volumetric dilution, rather than sequestration best explains the low vitamin D status of obesity. Obesity (Silver Spring). 2012 Jul;20(7)1444-8. doi: 10.1038/oby.2011.404 [Crossref][PubMed][Google Scholar]
25. Wortsman J, Matsuoka LY, Chen TC, Lu Z, Holick MF. Decreased bioavailability of vitamin $D$ in obesity. Am J Clin Nutr. 2000 Sep;72(3)690-3. doi: 10.1093/ajcn/72.3.690 [Crossref][PubMed][Google Scholar] 